\title{
Generation Y-Turnover: A Complementary Fit Perspective
}

\author{
Abdelbaset Queiri, Araby Madbouly \\ Muscat College, Muscat, Oman \\ abdelbaset@muscatcollege.edu.om, araby@muscatcollege.edu.om
}

\begin{abstract}
Generation Y becomes the main pillar of workforce around the world. This generation enters the workplace with different values and characteristics from their counterparts of other generational workforces. In Malaysia, generation Y employees are well known of their high job mobility. Human resource managers are in dilemma of how to retain this new workforce? This paper serves the purpose to respond to such queries by investigating the factors contributing to Generation Y employees' Turnover from a complementary fit perspective. This study was conducted in Malaysian Business Process Outsourcing Sector (PBO). The total sample was comprised of 318 respondents belong to generation Y employees. The data was analysed in Amos using two steps approach. Extrinsic, freedom and demand abilities fit were the predictors of Generation Y employees' intention to quit in Malaysian BPO sector.Using cross sectional method limits our understanding to whether the predictors of turnover intention were due to career effects or generational effects. This study provides empirical evidences to Malaysian HR Managers to what makes generation Y employees leave the organization. This is a better surrogate of the existed anecdotal information. Furthermore, this study informs HR Managers that stereotyping the findings from Western context may be treated with caution.
\end{abstract}

Keywords: Generation Y, Turnover, Complementary fit, Business process outsourcing sector

\section{Introduction}

The workforce demography has changed. Currently, the workplace comprises of three generational workforces, which are baby boomers, generation X and generation Y (Angeline, 2011). In Malaysia, the influx of the generation $\mathrm{Y}$ workforce into the different industries and sectors is at a high pace. Generation $\mathrm{Y}$ workforce is a source of sustainable competitive advantage; this generation represents over $50 \%$ of Malaysia's workforce. Out of the 12,675,800 employees that currently hold positions, the generation $\mathrm{Y}$ workforce represents approximately 6,267,200 of them (Malaysian Statistical Department, 2011). This workforce group is expecting to replace the retired individuals of baby boomers, as the latter have commenced their retirements since three years back and will continue to do so in the future. Generation X has been promoted to senior management positions (Josiam et al., 2009). This generation will soon become the main pillar of the workforce; hence, the transition towards knowledge based economy as a goal of 2020's vision lies on their shoulders (Angeline, 2011). Both theorist and academics recently have argued that this generation requires different set of HR practices to influence their attitudes and behaviours at the workplace (Twenge, 2010). In the past, both theorists and practitioners input more efforts in setting effective strategies to recruit and retain talented employees, most of which were developed based on employee life cycle needs, maturity (age) needs or based on career stage needs (Macky Gardner, and Forsyth, 2008). However, such criteria on employee selection and retention practices are rendered less effective and require reconsideration (Wan Yusoff, Queiri, Zakaria, and Raja Hisham, 2013). It is argued by a number of scholars on the worth of customizing recruiting and retaining strategies based on generational workforce differences, that is, the reality of the generational gap theory as prime criteria into understanding the attitudes and behaviours of the generational workforce are often overlooked (Wong, Gardiner, Lang, 2008; Giancola, 2006).

With the increased popularity of the generational gap concept, it is argued that each of the three existing generational workforces (i.e., Baby boomers, generation-X and generation- $Y$ ) was exposed to distinctive fundamental life events that have shaped distinguishable peer personalities and values/work values for each generational workforce, which are durable and resistance to change (Howe and Strauss, 2007). Consistent with this, empirical evidences based on longitude studies affirmed that the differences in work values and personality traits among the generational workforce are real scientific facts rather than being fiction (Twenge and Campbell, 2009). Contemporary, generational differences at the workplace is an equally, if not more important, criterion to be considered while setting recruiting and retaining human resource (HR) strategies (Westerman and Yamamura, 2007).This group of employees enters the workplace with desirable traits, such as: better education, technological savvy, the ability to multi-task, technically skilled, achievement oriented, 
culturally diverse and having sense of true empowerment (Han and $\mathrm{Su}, 2011$ ). However, this generation is well known of the increased job mobility. The turnover rate associated with the generation $Y$ workforce in Malaysia has been described to be unprecedented (Wan Yusoff et al., 2013). According to Malaysian human resource practitioners, generation $\mathrm{Y}$ employees change jobs frequently, the average tenure of the youngest employees estimated to be 18 months, compared to an average of 3 years for other generations (Sheahan, 2007). There is a deep concern on national and organizational level about the generation $Y$ workforce increased job mobility. According to The Malaysian Employers Federation (MEF) (2012), it costs RM 30,000 to replace an employee, which exceeds four times the cost of recruiting. Furthermore, the concern of increased job mobility at national level becomes more complicated, as the Malaysian Labor market currently experiences a shortage of talents and it is difficult to find an adequate employee (Marthandan et al., 2013).

Furthermore, the labor market increasingly faces the brain drain phenomenon, especially among adult workers, whereby Singapore becomes a favorite destination to most of them; the anticipated emigrants of educated adults in 2010 were 276,558, of which Singapore absorbs 44\% of them (Choong et al., 2013). In this vein, the literatures continue to prompt calls to examine variables, test models and create models to understand the reasons of high turnover rates of generation $\mathrm{Y}$ working adults in Malaysian context, in order to set effective retention strategies (Choong et al., 2013; Angeline, 2011; Solnet\& Hood, 2008). Despite the calls, empirical studies attempted to examine generation Y employees' intention to quit is quite limited, and the issue has not received substantial discussion in previous literature, as it is still regarded as uncharted territory and requires further investigation (Lee et al., 2012). In light of that generation Y employees are undergoing a radical change and since most supervisors and managers who hold senior positions in organisations belong to other cohorts (i.e., baby boomers, generation X), there is likelihood that the difficulty of retaining generation Y employees arises from insufficient understanding of generation Y employees' needs at the workplace. Eisner (2005) refers to this as the generational gap, that if not sufficiently addressed, the conflict at the workplace is inevitable, and that will entail adverse attitudes. In this vein, the focus is given to the lack of fit between the environment and generation Y employees' expectations and work values as the cause of turnover intention. More specifically, the complementary fit perspective as a branch of person environment fit is utilised to investigate the specific dimensions of complementary fit facets and their impact on generation Y employees' intention to quit.

\section{Literature Review}

Person-Environment (P-E) Fit: Drawing from Lewin (1935), neither personnel characteristics nor environment adequately explains the great amount of variance in attitudes or behaviors. It is rather the interaction of both (P X E) that would be expected to explain a larger amount of variance in an individual's attitudes (Kristof-Brown et al., 2005). The theory of work adjustment developed by Dawis et al. in 1968postulates that, due to the mutual obligations on one another (person and environment), a state of correspondence is required between individual and environment at the workplace, in order to achieve successful work relations, adjustment constitutes the means to maintain these good relations. The third proposition of theory of work adjustment explicitly states that the correspondence state, or alternatively fit, is an inducement of job attitudes. Similarly, the theory of needs fulfilment proposed by Locke in 1976 underpinned on the principle of person-environment fit. This theory explains that job satisfaction and other positive job attitudes are the function of one's perception that his/her needs/values are. In addition, Edwards (1996) argues in the context of Nomo-logical network that another distinct stream is explained by P-E fit theory, which is job stress. Based on cybernetics theory of self-regulatory, Edwards (1996) declared job stress to be a consequence of the discrepancy between person and environment fit. The notion of cybernetic theory stipulates that the discrepancies between environmental inputs and internal standards should be kept at minimum. Two possible reasons for this stress to occur are, either the individuals lack the abilities to meet environmental (work) demands, or, there is a shortage in fulfilling needs of individuals at the workplace.

Conceptualization of Person-Environment Fit: Kristof (1996) responded to the ambiguity surrounding the P-E fit concept, as people tend to interpret fit differently. Subsequently, P-E fit has been conceptually divided into two main domains: supplementary fit and complementary fit. The four aforementioned domains of P-E fit have been grouped under either complementary or supplementary fit. 
The work of Kristof (1996) refined the fit definition whereby supplementary fit refers to a person that possesses characteristics similar to other individuals in an environment and both environment and individual place the same importance on dimensions. Such dimensions could be either in goals, values or in personality traits (Edwards \&Billsberry, 2010). On the other hand, complementary fit posits that a good fit exists as the reciprocal requirements of individuals and environment are fulfilled. Thus, a complementary fit occurs when organizations fulfil the requirements of their employees or employees fulfil the requirements of organizations. Both types of fit can be distinguished from conceptual perspective, instead of content perspective, whereby complementary fit is the desire amount of an attribute that influence job related attitudes, therefore, meeting individual needs (desire) is more proximal measure to attitudes more than placing similar importance on particular dimensions. However, the role of Supplementary fit influencing attitudinal outcomes has been recognised in the literature. In Byrne's similarity attraction paradigm (1971) and Van Vianen (2000) argued that supplementary fit is a mean of meeting personal needs. In the sense, consensual validation is a need for the individuals which can be achieved at person-person level. Albeit that, fulfilling complementary fit aspects are more direct in influencing and interpreting attitudinal outcome, as complementary fit emphasises on directly meeting the needs of individuals at workplace (Kristoff et al., 2005).

Work Values Fit and Intention to Quit: According to Liu et al. (2010), organisations should pay attention to the congruity of the supplied work values of their employees. Elfenbein and O'Reilly (2007) contend that the willingness of employees to remain with their organisation is subjected to the extent of fulfilling their work values through human resource functions. Moynihan and Pandey (2007) found that employees have less intention to quit when they experience better fit with their organisation. Drawn from generational theory notion, the generation Y workforce is of different paradigm when compared to its counterparts. In essence, generation Y emphasizes on certain work values; such work values are developed at early stage of adolescence and peaked during adulthood. Accordingly, Cennamo and Gardner (2008) anticipated that generation Y employees will experience less fit, since the most senior positions are occupied by the older groups who belong to previous generations that hold different work values. Thus, if the preferred work values of generation Y employees are unmet, it will probably result in triggering their intention to quit. Kim et al. (2009) added to the above argument, that, loyalty is not a generation Y characteristic.It would be expected that generation $Y$, whose preferred work values are not actualised, will have the intention to leave the organisation. Given the contradictory discussion on the preferences of work values of generation $Y$ at the workplace, besides the limited scholarly work in this regard, the influence of the five work values fit on the intention to quit has remained empirically unjustified for the generation Y workforce in Malaysia (Queiri et al., 2014). If Malaysian generation $Y$ employees have preferences towards particular work values, this, in return, may affect their intention to quit, especially with increased mobility and impatience of generation Y. Consequently, it could be hypothesised:

H1a: Extrinsic work values fit will negatively influence Generation Y's intention to quit.

H1b: Intrinsic work values fit will negatively influence generation Y employees' intention to quit.

H1c: Status work values fit will negatively influence generation Y employees' intention to quit.

H1d: Freedom work values fit will negatively influence generation Y employees' intention to quit

H1e: Altruistic work values fit will significantly and negatively influence generation $Y$ employees' intention to quit.

Demands Abilities Fit and Intention to Quit: Hassan et al. (2012) conducted an empirical study and found that poor match between the assigned tasks and one's abilities (DA misfit) will induce the turnover intention positively. As, DA fit is about matching the knowledge, skills and abilities (KSAs) of employees with the demands of the job, hence lower the fit is the high turnover rate and more absenteeism will be the result if a good fit does not exists. Mathis and Jackson (2003) individuals who experience a mis-fit between their own abilities and complexities of the job will have an intention to leave their job for another job in which they perceive better utilisation for their skills and knowledge through providing job tasks which better suit their abilities. In this vein, the impact of demand abilities fit in terms of utilisation generation Y employees' skills, abilities and knowledge on intention to quit is not investigated within Malaysian context, and however, it is reasonably to hypothesis the following:

H1f: Perceived demands abilities fit will negatively influence generation Y employees' intention to quit. 


\section{Mediating Role of Job satisfaction, Affective commitment and Job Stress}

In view of the discussed theoretical background, the perceived fit with preferred work values and demand abilities may exert an influence on employees' job satisfaction and affective organisational commitment and job stress. This is an indication that the relationship between the perceived work values fit and demand abilities with intention to quit is more complex than a direct relationship. Westerman and Cyr (2004), Liu et al. (2010) and Aurther et al. (2006) empirically justified that needs-supplied fit influences on intention to quit are mediated by job satisfaction and affective organisational commitment. Solnet and Hood (2008) in their turnover model specifically tailored for generation Y workforce, proposed the alignment of HR practices with generation Y work values, in other words fit is a determinant of work related attitudes that in return may exert an influence on intention to quit. Calisir et al. (2011) and Deery (2008) based on reviewing wide range of empirical studies, job satisfaction and effective organisational commitment to be among the direct and strongest antecedents of the intention to quit. Consistent with this, their empirical findings affirmed that job satisfaction and affective organisational commitment where strongest predictors of intention to quit and such job attitudes mediate the relationship between organisational factors and the intention to quit. Accordingly, given the potential impact of the preferred work values fit and demand abilities fit on job attitudes, in addition to the influences of such job attitudes on the decision to leave organization. It is of important to highlight that the preferred work values for generation Y employees in Malaysia are not known. Thus, all the perceived fit with work values are hypothesized, in effort of attempting to find out which of the particular type of fit may influence the intention to quit through evoking psychological response at first place. Hence, it is reasonably to states the following hypothesizes:

H2a: Job satisfaction will mediate the relationship between the (extrinsic, intrinsic, status, freedom and altruistic) works values fit and intention to quit.

H2b: Job satisfaction will mediate the relationship between the demands abilities fit and intention to quit.

H3a: Affective organizational commitment will mediate the relationship between the (extrinsic, intrinsic, status, freedom and altruistic) works values fit and intention to quit.

H3b: Affective organizational commitment will mediate the relationship between the demands abilities fit and intention to quit.

Drawing from the theoretical discussion that highlights the likelihood of complementary fit (demands abilities fit and different aspects of work values fit) to influence job stress, it is reasonable to conclude that unmet preferred work values or mismatch of abilities will result in job stress. With this said, large body of literature considers intention to quit as consequence of job stress. Similar to the other generational workforce, when generation Y employees experience stress at their jobs due to unmet preferred rewards or assigned tasks to employee that not within his skills, it is likely that such feeling would result in triggering the intention to quit job. Job stress is considered one of the major personal attributes that consistently found to be positively related to the intention to quit (Firth et al., 2004). Accordingly it is hypothesized as following: H4a: Job stress will mediate the relationship between the perceived (extrinsic, intrinsic, status, freedom and altruistic) works values fit and intention to quit.

H4b: Job stress will mediate the relationship between the perceived demands abilities fit and intention to quit.

Job Related Attitudes and Turnover Intention Griffeth and Hom (1995) conducted a meta-analysis of employees' turnover antecedents and correlates, which is updated in Griffeth, Hom and Gaertner (2000). The latter Meta-analysis reconfirmed the finding that overall job satisfaction and organizational commitment were the best direct predictors of turnover intention; the comparison was conducted with personnel characteristics factors (e.g., gender, tenure, educational level and job category), work experience factors (e.g., advancement, leadership, participation and co-work group cohesion), and external work environment factors (e.g., perceived alternatives). However, the crux of debates was surrounded by which of the two work related attitudes was more closely related to the turnover intention (Deery, 2008). Despite the perplex results in the organizational behavior field, Griffeth et al. (2000), Shore and Martin (1989) and Porter et al. (1974), agreed based on empirical findings and meta-analysis approaches that organisational commitment is a stronger predictor of turnover intention. Thus, it is more closely related to turnover intention. They further argued that a global attitude, such an organisational commitment, is closely associated with organisational behavioural outcomes such as intention to quit. Nevertheless, for generation Y workforce it is argued that overall job satisfaction is a stronger predictor than affective organisational commitment and job stress for turnover intention (Solnet and Hood, 2008). Probably, generation Y employees strive for self-actualisation, 
and can move from one organisation to another that provides better opportunities of fulfilling selfactualisation needs. This makes the commitment to their careers instead of their organisations, which may explain the weakness of affective organisational commitment and job stress in predicting turnover intention compared to job satisfaction. Additionally, job stress predictive strength of turnover intention of generation $Y$ employees is less than job satisfaction and affective organisational commitment. This concurs with Firth et al. (2004) finding, Griffeth et al. (2000) meta-analysis finding, and Nee et al. (2013) finding on turnover intention antecedents for the all employees and for generation $Y$ employees, respectively. Therefore, it could be reasonably to hypothesise the following;

H5: Job satisfaction will be a stronger predictor of generation Y employees' intention to quit more than affective organisational commitment and job stress

\section{Methodology}

Sample and data collection: A paper and pencil survey was administrated to employees who fall under the generation Y workforce during office hours and breaks. Generation Y employees (born from 1980 until 2000) in the Business Process Outsourcing (BPO) sector is the target population. In total, a total of 350 responses were collected, and the data screening suggests that 318 responses should be retained for further analysis. Thirty two responses were excluded, as two of them have missing data over $5 \%$. The other 30 responses were excluded based on the sampling criteria guidelines; these 30 responses indicated that they were not born between 1980 and 2000. This left the researcher with 318 responses, which met the sampling criteria and missing data of less than $5 \%$ was treated by mean substitution method. Table 1 reflects the demographical profile of the respondents.

Table 1: Demographical Profile of Respondents

Gender (\%)

Male: $43 \%$

Female: $57 \%$

Ethnicity (\%)

Malay:28\%

Chinese: $49 \%$

Indian:23\%

Tenure (\%)

Less than 1 year : $42 \%$

1-3years: $40 \%$

More than 3 years: 18\%

Educational level (\%)

Diploma: 21\%

Degree:70\%

Master:9\%

Job Categories (\%)

Non-executive:21\%

Executive: $69 \%$

Managers:10\%

This study uses the Work Values Scale (WVS) developed by Lyons (2004), which consists of 31 items that can represent five work values dimensions (extrinsic, intrinsic, status, freedom and altruistic values). The fit is assessed through indirect subjective fit, whereby work values are asked twice: first as desirable work values, and second as perceived work values of the organisation, based on commensurate work values measure for both forms. Accordingly, the respondents are given the following two tasks: a) Please indicate the desirability level of having a job with these items (individual form or ideal form). b) To what extent are these items provided by your present job (perceived organisational supply form). The work values fit on each dimension is measured by calculating the discrepancies between the items provided in individual form and perceived organisational supply ( differences between paired items), thus creating a fit profile (D-score) (Westerman\& Yamamura, 2007). Van vianen (2000) defines the D-score profile as a profile comparison method whereby fit is calculated as the difference between an individual's work values with others' perceived work values. A positive sign indicates that there is under fit, and a negative sign indicates that there is over fit. The response for both forms is based on a five point scale. 
For ideal form, 1 indicates the item is very undesirable and 5 indicate the item is very desirable. For perceived supply form, 1 indicates that the item is supplied with very little extent and 5 indicate a very large extent. Demands abilities fit - It is measured directly using the perceived direct fit using four items. Participants are asked to respond on a five-point Likert scale; 1 indicates "strongly disagree" and 5 indicates "strongly agree". The items of demand abilities fit were originally combined from (Giauque et al., 2014; Schmitt et al., 2008; Cable \& DeRue, 2002).

Job satisfaction - is measured using five items on a five-point Likert scale, as provided by Hochwarter et al. (2003). This measure is suitable for the current study, as it reflects the overall job satisfaction, rather than questioning the satisfaction with different aspects of work.

Affective organisational commitment - It is measured using Allen and Meyer's (1990) scale, which consists of five items, and the response is on a 5-point Likert scale.

Job Stress - It is measured using House and Rizzo's (1972) scale, which consists of six items on a five-point scale. Originally, House and Rizzo's (1972) scale to measure job stress consists of 7 items. However, the seventh item "I have felt nervous before attending meetings at work" was removed from the scale, as it was deemed to be irrelevant in the Malaysian context, since a large number of the targeted population do not attend meetings often.

Analysis: This study relies on the two-step approach suggested by Anderson and Gerbing (1988) to perform the analysis stage, measurement and structural models. However, prior to the implementation of the two step approach, exploratory factor analysis (EFA) was employed to group the multiple indicators to their corresponding constructs according to the content. The measurement model is implemented with use of confirmatory factor analysis (CFA). Anderson and Gerbing (1988) recommend the use of CFA to achieve the uni-dimensionality of constructs. The ultimate goal of the measurement model is to achieve a construct validity and reliability. Using structural equitation modelling, the proposed hypothesises were examined.

\section{Results}

Prior to the exploratory factor analysis (EFA) implementation, several assumptions were investigated to judge on the appropriateness of implementing EFA. These assumptions are the sample size, factorability and univariate normality of items, as recommended by Hair et al. (2006). The individual form of the work scale (WVS) that consists of 31 items was found to satisfy such conditions. The implementation of EFA has generated five factors that measure 17 items. The exclusion criteria for the rest of the items is based on items that have a factor loading value under 0.4 , which is removed and items that cross load on other factors is removed as well. Following the recommendation of Stevens (1992), 0.4 is the cutoff value of the factor loading, since a lower value can reduce the model goodness of fit. Furthermore, the assumptions of EFA were satisfied for all the items of Demand abilities fit, job satisfaction, affective organisational commitment, job stress and intention to quit. EFA is also implemented with these constructs separately, to establish a single factor solution. Measurement Model using confirmatory factor analysis (CFA), the goodness of fit for the five generated factors is collectively assessed. These factors are: intrinsic, extrinsic, status, freedom and altruistic work values, which measure 17 items. To assess the goodness of fit, several indices are used, following the recommendation of Hu \&Bentler (1999) and Hair et al. (1998). The fit indices suggest that the model provides an adequate fit to the data, Table II Goodness of fit for work values model (individual form), as displayed in Table 2. Similarly, the goodness of fit for the five factors with 17 items that reflect organizational items is assessed using CFA. The work values model for organizational form shows a reasonable fit to the data, with $x^{2}=424 ; \mathrm{p}<0.01 ; \mathrm{df}=90, \mathrm{SRMR}=0.069, \mathrm{CFI}=0.90$ ) . 
Table 2: Goodness of Fit for Work ValuesModel (Individual Form)

\begin{tabular}{llll}
\hline Fit index & Recommended values & \multicolumn{2}{c}{ Observed Values } \\
\hline $\mathrm{x}^{2} / d f,\left(\mathrm{x}^{2}, d f\right)$ & $\mathrm{x}^{2} / d f \leq 3$ & 1.89 & $(171,90)$ \\
CFI & $\geq 0.90$ & & 0.94 \\
RMSEA, Pclose & $\leq 0.08$, Pclose $\geq 0.05$ (no.sig) & 0.053 & 0.32 \\
TLI & $\geq 0.90$ & & 0.92 \\
SRMR & $\leq 0.08$ & & 0.053 \\
GFI & $\geq 0.90$ & & 0.94 \\
AGFI & $\geq 0.80$ & 0.91 \\
\hline
\end{tabular}

All the fit statistics fall within the range of the recommended values, as advised by Hu \&Bentler (1999) and Hair et al. (1998). Additionally, the goodness of fit for demand abilities fit (DA), job satisfaction (JSAT), affective organizational commitment (AOC), job stress (JS) and intention to quit (IQ) are assessed separately through CFA. The fit indices are shown in Table III. All the constructs show adequate fit to the data. Table 3 Goodness of fit for research constructs. The respondents should be invariant (equivalent) to the factors structure and to the corresponding items loading on the factors. Thus, the interpretation of the subsequent analysis becomes more meaningful (Milfont\& Fischer, 2010).

Table 3: Goodness of Fit for Research Constructs

\begin{tabular}{lllll}
\hline Construct & $\left(\mathbf{x}^{2}, \mathbf{d f}\right)$ & CFI & RMSEA & Pclose \\
DA & $(4.683,2)$ & 0.99 & 0.065 & 0.28 \\
JSAT & $(0.853,1)$ & 0.99 & 0.01 & 0.526 \\
AOC & $(12,4)$ & 0.99 & 0.08 & 0.134 \\
JS & $(1.8,1)$ & 0.99 & 0.05 & 0.339 \\
IQ & $(3,1)$ & 0.99 & 0.08 & 0.158 \\
\hline
\end{tabular}

Vandenberg and Lance (2000) provided good guidelines for establishing invariance measurement. It is suggested that configural invariance is assumed as long as the unconstrained model shows a goodness of fit when two groups (male and female) are under the analysis. Table 4 presents the goodness of fit for the unconstrained model for both groups. All the fit statistics indicate that the goodness of fit is adequate, based on Hair et al. (1998) suggestion. Thus, the configural invariance is assumed for male and female. The configural model will serve as the baseline model for subsequent analysis of invariance. Furthermore, the metric invariance test is employed through constraining all items across the two groups to be equal. It is observed that there is a metric invariance between male and female if the full constrained model's goodness of fit has not reduced significantly when compared with the baseline model (unconstrained model). Bentler (1990) suggests the use of $\triangle \mathrm{CFI}$, where the metric invariance model's goodness of fit is said to be significantly reduced if the $\Delta$ CFI is reduced by more than 0.01 when compared to the baseline model. However, the reduction of $\triangle \mathrm{CFI}$ is equal to 0.008 . 
Table 4: Invariance Analysis

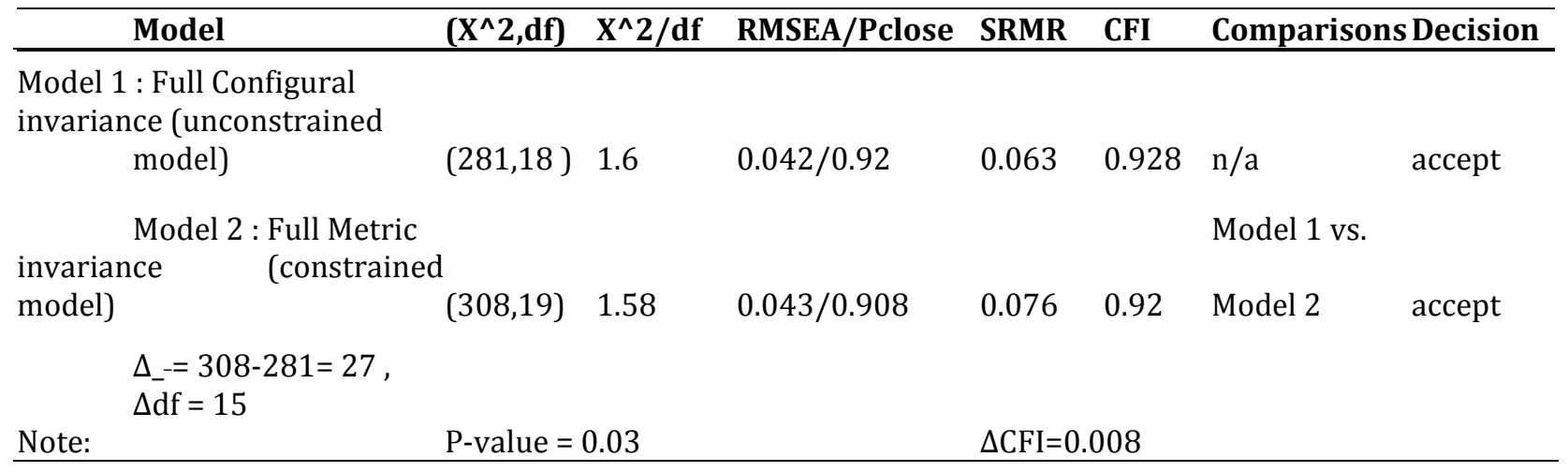

The presence of common method effects is assessed through Harman's single-factor test in SPSS. The test is implemented by extracting a single factor solution. A common method effects is present if the extracted one factor accounts for the majority of variance, which is over $50 \%$ (Calisir et al., 2011). A single factor solution accounts for $32.345 \%$ of the variance. Hence, it is not a majority, and the Harman's test indicates that the constructs measurement is due to more than a common methods effects. The AVE and CR are estimated for each factor and the calculated values are presented in Table 5. Despite that AVE for EWV, IWV and FWV are below the threshold of accepted AVE. Nevertheless, Fornell and Larcker (1981) argued that an AVE of less than 0.5 is acceptable given that the CR is above 0.6. Such criteria is used in a wide range of management researches, as in Kim et al. (2009), who decided to proceed with analysis under such low AVE. Additionally, the AVE for constructs is quit close to 0.5. In terms of discriminant validity, it is assessed using the guideline provided by Fornell and Larcker (1981). Discriminant validity is achieved if the average variance extracted for each factor is larger than the shared variance with any factor. For instance, as shown in Table5, the average variance of FWV (0.486) is larger than any shared variance that FWV shares with other factors, and the same is applied to the remaining factors. Accordingly, each factor measure is distinct from the others, with no overlapping or possible co-linearity.

Table 5: CR, AVEs and Shared Variances

\begin{tabular}{|c|c|c|c|c|c|c|}
\hline & $\begin{array}{l}\text { Composite } \\
\text { Reliability } \\
\text { (CR) }\end{array}$ & $\begin{array}{l}\text { Average variance } \\
\text { extracted(AVE) }\end{array}$ & FWV & EWV & IWV & SWV \\
\hline FWV & 0.739 & 0.486 & 0.486 & & & \\
\hline EWV & 0.744 & 0.421 & 0.401 & 0.421 & & \\
\hline IWV & 0.746 & 0.382 & 0.219 & 0.327 & 0.382 & \\
\hline SWV & 0.753 & 0.513 & 0.217 & 0.053 & 0.163 & 0.513 \\
\hline AWV & 1 & 1 & & & & \\
\hline
\end{tabular}

Similarly, convergent validity for the job satisfaction, affective organisational commitment, job stress and demand abilities fit are assessed to measure the extent that the items reflect the theoretical concept. Using same criteria provided by Bagozzi et al. (1991) which suggested that convergent validity is established through assessing three different dimensions. The calculated average variance extracted was above 0.5, except for job stress. According to Fornell and Larker (1981) and Huang et al. (2013), even if the average variance extracted is less than 0.5 , provided that composite reliability is higher than 0.6 , the convergent validity of the construct is still acceptable. With reference to Table 6 all the constructs have composite reliabilities above 0.6. Thus, it is concluded that the different constructs have a convergent validity, and naturally have discriminant validity, since these factors (job satisfaction, job stress, and affective organisational commitment and demand abilities) are theoretically distinctive from each other and each factor measures a different concept. 
Table 6: Constructs' Validity

\begin{tabular}{|c|c|c|}
\hline Construct & $\begin{array}{l}\text { Average Variance } \\
\text { (AVE) }\end{array}$ & $\begin{array}{l}\text { Extracted } \\
\quad \text { Composite Reliability (CR) }\end{array}$ \\
\hline Demands Abilities Fit (DA) & 0.591 & 0.851 \\
\hline Job Satisfaction (JSAT) & 0.745 & 0.921 \\
\hline \multicolumn{3}{|c|}{ Organisational } \\
\hline $\begin{array}{l}\text { Commitment } \\
\text { (AOC) }\end{array}$ & 0.665 & 0.908 \\
\hline Job Stress (JS) & 0.33 & 0.603 \\
\hline Intention to Quit & 0.756 & 0.902 \\
\hline
\end{tabular}

The path coefficients enable us to draw some conclusions concerning the hypothesized relationships. H1a until H1f theorized that fit with different work value dimensions would be negatively related to the turnover intention of generation Y employees. The structural model supports (H1d) that is the fit with freedom work value exert direct influence on the turnover intention of generation Y employees. Such result is indicated in Table 7. To assess the mediating role of job related attitudes in linking work values fit dimensions to the turnover intention, different path model was analyzed in order to assess the unique contribution of each theorized mediator, instead of collective assessment of these mediators. Each potential mediator is assessed separately to make an inference of which of the potential mediators explain the intention to quit for generation Y employees. H2a received partial support, as job satisfaction was found to mediate the relationship between extrinsic and freedom work values. Furthermore, H2b received full support, as demand abilities fit has indirect influence on the turnover intention, through job satisfaction.Additionally, H4a received partial support, as freedom work values fit was found to exert indirect influence on the turnover intention, through job stress. On the other hand, H3a-b did not receive support, in the sense affective organizational commitment was irrelevant mediator in explaining generation Y turnover intention, as well as $\mathrm{H} 4 \mathrm{~b}$ was not supported either. The results of mediation test are presented in Table 8.

Table 7: Direct Impact on Turnover Intention

\begin{tabular}{|c|c|c|}
\hline Dependent variable & Independent variables & Direct effects \\
\hline \multirow[t]{6}{*}{ Intention to quit (IQ) } & Job satisfaction (JSAT) & $-0.552^{* *}$ \\
\hline & Affective organizational commitment (AOC) & $-0.168^{* *}$ \\
\hline & Job stress (JS) & $0.124^{* *}$ \\
\hline & Extrinsic work values fit (EWV fit) & 0.105 \\
\hline & Intrinsic work values fit (IWV fit) & -0.108 \\
\hline & Status work values fit (SWV fit) & 0.020 \\
\hline${ }^{*} P<0.05$ & Freedom work values fit (FWV fit) & $-0.112^{*}$ \\
\hline \multirow{6}{*}{${ }^{* *} p<0.01$} & Altruistic work values fit (AWV fit) & -0.029 \\
\hline & Demand ability fit (DA) & -0.033 \\
\hline & Gender & -0.031 \\
\hline & Tenure & 0.080 \\
\hline & Job Category & -0.037 \\
\hline & Educational Level & 0.006 \\
\hline
\end{tabular}


Table 8: Mediation Test

\begin{tabular}{lllll}
$\begin{array}{l}\text { Dependent } \\
\text { variable }\end{array}$ & Independent variables & $\begin{array}{l}\text { Indirect } \\
\text { (JSAT) }\end{array}$ & Indirect (AOC) & Indirect (JS) \\
\hline Intention to Quit & Extrinsic work values fit (EWVfit) & $\mathbf{- \mathbf { 0 . 0 7 3 } ^ { * }}$ & -0.021 & -0.007 \\
& Intrinsic work values fit (IWVfit) & -0.072 & -0.020 & 0.005 \\
& Status work values fit (SWVfit) & 0.060 & 0.039 & -0.013 \\
& Freedom work values fit (FWVfit) & $\mathbf{- \mathbf { 0 . 1 3 0 } ^ { * * }}$ & -0.038 & $\mathbf{- 0 . 0 3 5 ^ { * }}$ \\
${ }^{*} \mathrm{P}<0.05,{ }^{* *} \mathrm{P}<0.01$ & Altruistic work values fit (AWVfit) & -0.038 & -0.022 & -0.014 \\
& Demand ability fit (DA) & $\mathbf{- 0 . 2 3 0}^{* *}$ & -0.067 & -0.038 \\
\hline
\end{tabular}

Discussion: First aim of this study was to determine which types of complementary fit dimensions are relevant in explaining generation Y employees' intention to quit. Freedom work values fit, extrinsic work values fit and demands abilities fit were relevant predictors of generation $Y$ employees' intention to quit, with freedom work values fit to be the strongest direct predictor. A high preference towards freedom work values could be linked to the decline of work centrality; generation $Y$ had witnessed their parents to be work-centric and devote a huge time to work, and in return they fell victims to economic shrinking measures (retrenchment and unstable salaries; Kowske et al., 2010). This, in turn, influences generation Y towards the concept of live to work instead of work to live (Twenge, 2010). This is also particularly true in Malaysia, as the country went through economic uncertainties when generation $Y$ was at the developmental stage, which are the same reasons that cause them to place higher emphasis on freedom work values. They expect a workplace that provides a balance between life's and family's responsibilities with work, besides preferences of convenient working hours that suit their life schedule. They also expect workplace engaged in leisure and workplace fun activities instead of taking the workplace very serious. Generation Y are said to exhibit citizenship behaviour outside the workplace. This, in turn, leads to generation Y seeking a balance between work and life. However, generation Y does not necessarily exhibit citizenship behaviour in the workplace, as this generation perceives the workplace as a means to an end rather than an end in itself.

It could be argued that Malaysia's generation Y employees grew up in a collective society, which consequently causes them to be more committed to a work-life balance in order to cater the needs of families or personal life, which, in the end will bring benefits to the entire family. Therefore, freedom work values fit is extremely salient for generation $Y$ employees, as they regard freedom work values to be a necessity instead of a luxury, and therefore, if it is not adequately supplied, the impatience and low tolerance of such stressors (work-life conflict, inconvenient long working hours and serious workplace environment) will drastically result in a high level of generation Y mobility. Furthermore, this generation is confronted with new economic trends and has financial obligations ahead. For instance, this group of employees needs to cope with the rapid inflation of living expenses, increased higher education costs, and the associated load of debt. Therefore, it is very likely that there will be high preference towards extrinsic work values. Alternatively, the high emphasis on extrinsic work values could be as response of the economic hardships experienced during formative years.

Apart from preferences towards material possession and benefits, having friendly co-workers and supportive supervisors as part of extrinsic rewards could be meaningful in explaining generation Y employees' attitudinal outcomes and behavioural intention once there is a good fit. The need of friendly co-workers reflects that generation Y employees are seeking for social interaction, and they do not have less attention towards social interaction activities. Despite the generation Y cohort being digitally connected and available online 24/7, social interaction at the workplace matters for them. As culture plays a vital role in shaping the preferences of work values, Malaysia is known as a collective society. Such cultural belief seems to be embraced by the generation Y workforce in Malaysia, and this is brought with them into the workplace. This collectivist culture belief is demonstrated by more demands of relationship and interpersonal factors by the generation Y workforce. In line with this, Ching and Kee (2012) found empirical support that the collectivist cultural orientation influences the choice of social values, and thereafter, such values have an impact on work 
related attitude aspects. On the other hand, intrinsic work values fit, status work values fit and altruistic work values fit are found to be irrelevant for generation Y employees' intention to quit. Collectivistically oriented individuals would endorse more group-linked work values (e.g., interpersonal relations). Indeed, the work values held by Malaysians reflect the cultural orientation that exists in their society. On the other hand, individualism asserts that "the individual is autonomous from the group". In individualistic societies, the core values are individual achievement, self-reliance, belief in equality of opportunity, competitiveness, hard work, informality and belief that change is good (Ching and Kee, 2012). Given that collectivism is a dominant value in Malaysia, the status work values may not be vital in determining generation Y's future career. It is also likely that individualism may not be a character of the Malaysia's generation Y employees, and thus, the group is realistic towards the need of status work values.

Moreover, this may explain why the status work values fit was irrelevant in explaining the decision to quit and career path for Malaysia's generation Y employees compared to extrinsic/social rewards. Demands abilities fit for generation $\mathrm{Y}$ employees is in line with notion of P-E fit theory ,that complementary fit dimensions and turnover intention is more complex than a direct relationship. It would be expected that the relationship between demand abilities fit and intention to quit for generation $\mathrm{Y}$ employees to be in line with Westerman and Cyr (2004), Liu et al. (2010) and Arthur et al. (2006) who affirmed that fit at first place affects employees' job attitudes and thereafter intention to quit. In contradiction of Meyer et al. (2002), Griffeth et al. (2000), Shore and Martin (1989) and Porter et al. (1974), this study revealed that overall job satisfaction is a stronger predictor than affective organisational commitment for turnover intention, specifically for generation Y employees. Probably, the earlier studies focused on other generational workforce, as by that time of studies, generation $Y$ employees were not in a large numbers. There is a possible interpretation for such current findings which opposed the traditional theory. Indeed, generation $\mathrm{Y}$ employees strive for self-actualisation, and can move from one organisation to another that provides better opportunities of fulfilling self-actualisation needs. This makes the commitment to their careers instead of their organisations, which explains the weakness of affective organisational commitment in predicting turnover intention compared to job satisfaction. Indeed, it was argued that generation Y employees begin their careers with the assumption that they will change jobs frequently; therefore, if they are not satisfied with working at a company, they will leave. Furthermore, the contemporary dynamic environment has resulted in changes of the career traditional management system, which emphasises on the individual in developing careers (Baruch, 2006). Accordingly, career development becomes an individual responsibility, and several concepts, such as protein career "career resilience", is growing among professionals (Baruch, 2006). It is likely that a generation $Y$ cohort witnesses such changes, and given their high level of mobility compared with other generational workforces, this generation is expected to be committed to their careers and not to the organisations. In turn, this signifies that the role of affective organisational commitment as a mediator will probably not hold true for the generation $\mathrm{Y}$ workforce, and the job satisfaction role as mediator becomes more pronounced.

\section{Managerial Implication}

Indeed, the BPO sector suffers from non-attractive fringe benefits (monetary and non-monetary) when compared with other sectors (Wan Yusoff et al., 2013). Given this, managers in the BPO sector should reconsider their fringe benefits directed to generation $Y$ employees as part of their retention strategy, or to conduct mentoring sessions to discuss the potential of fringe benefits increases. The relationship with supervisors is essential in retaining this generation workforce; this generation lacks the direction and requires constant support from their supervisors to rapidly achieve success. With this respect, managers should enhance the relationship between supervisors and generation Y employees through developing coaching and monitoring programs to ensure that generation $Y$ employees receive immediate and constant feedback. However, feedback should be constructive and not carrying cynicism. Also, Managers should increase generation Y employees' cohesion with each other and ensure there is no conflict among them on a regular basis, and whether any possible remedies can be introduced to mitigate the conflict. Fairness of a company's policy requires managers' consideration when the improvement of retention for generation $\mathrm{Y}$ employees is the aim. Generation Y employees are said to have a sense of entitlement (disconnection of rewards and performance; Queiri, Dwaikat and Wan Yusoff, 2014). Therefore, this generation may perceive 
incremental bonuses or other rewards based on performance that are issued to others as to be applicable to them as well, regardless of their performance.

Thus, perception of inequity increases among generation $\mathrm{Y}$ employees, and judge the situation to be treated with partiality. Managers could tackle this issue by adopting gain sharing (GS) schemes, which are based on common fate concepts. This, in turn, may mitigate the perception of unfair policies associated with sense of entitlement and encourage teamwork that generation Y comforts with to carry out social interactions with others. Managers in the BPO sector should reconsider the freedom rewards directed for generation $\mathrm{Y}$ employees to improve generation $\mathrm{Y}$ employees' retention. Part of the retention strategies that enrich the freedom rewards is providing a balance between life/family and work. This could be achieved by giving generation $\mathrm{Y}$ employees the choice they perceive convenient to decide when to start and to stop work, in order to handle life/family responsibilities, instead of routine working hours. Other than that, reconfiguring the number of days to work may be beneficial to them. For instance, instead of working five days, gen eration Y employees are given the option to compress working days to four days, with more working hours per day. Other choices to enable balance between work and life may be a special on site area for employees' children. The retention strategy to enrich freedom rewards should go beyond providing a work life balance to incorporate fun activities at the workplace. Introducing more leisure time with intervention of fun activities could be an affective retention strategy resonated for generation Y employees. Fun activities are achieved through making the workplace less serious. Managers can incorporate task activities that provide pleasure, amusement and enjoyment. Sponsorship hobby activities could be incorporated into the job.Demand abilities fit is another crucial factor in retaining generation Y employees in the BPO sector. This signifies that managers should use generation $\mathrm{Y}$ employees' full potential through assigning tasks and duties that are relevant to their KSA's, where generation Y employees find themselves excelling and performing better. It is likely that recruited generation $\mathrm{Y}$ employees are technical savvy and possess vocational professionalism, and demands to be treated professionally. Therefore managers should avoid assignments that underutilise or miss-utilise their KSA's.

\section{References}

Allen, N. J. \& Meyer, J. P. (1990). The measurement and antecedents of affective, continuance and normative commitment to the organization.Journal of occupational psychology, 63(1), 1-18.

Anderson, J. C. \& Gerbing, D. W. (1982). Some methods for respecifying measurement models to obtain unidimensional construct measurement".

Angeline, T. (2011). Managing generational diversity at the workplace expectations and perceptions of different generation's expectations and perceptions of different generations.African Journal of Business Management, 5(2), 249-255.

Arthur, J. W., Bell, S. T., Villado, A. J. \& Doverspike, D. (2006). The use of personorganization fit in employment decision making: An assessment of its criterion-related validity.Journal of Applied Psychology, 91(4), 786-801.

Bagozzi, R.P., Yi, Y. \& Philips, L.W. (1991).Assessing construct validity in organizational research.Administrative Science Quarterly, 36, 421-58.

Baruch, Y. (2006). Career development in organizations and beyond: Balancing traditional and contemporary viewpoints. Human Resource Management Review, 16, 125-138.

Bentler, P.M. (1990). Comparative fit indices in structural models.Psychological Bulletin, 107(2), 238-46.

Byrne, D. E. (1971). The attraction paradigm. Academic Pr.

Cable, D. M. \& DeRue, D. S. (2002). The convergent and discriminant validity of subjective fit perceptions.Journal of Applied Psychology, 87(5), 875-884.

Calisir, F., Gumussoy, C. \& Iskin, I. (2011). Factors affecting intention to quit among IT professionals in Turkey.Personnel Review, 40(4), 514-533.

Cennamo, L. \& Gardner, D. (2008). Generational differences in work values, outcomes and person organisation values fit.Journal of Managerial Psychology, 23(8), 891-906.

Ching, S. \& Kee, D. (2012). Work values-career commitment relationship of generation y teachers in Malaysia, International Conference on Economics Marketing and Management, IACSIT Press, Singapore, pp. 242-246. 
Choong, Y. O., Keh, C. G., Tan, Y.T. \& Lim, Y.H. (2013). Propensity to Work Abroad Amongst Generation Y Working Adults in Malaysia, Proceeding of the International Conference on Social Science Research , World Conferences , Penang, Malaysia, pp. 695-705.

Dawis, R. V., Lofquist, L. H. \& Weiss, D. J. (1968). A Theory of Work Adjustment: A revision. Minnesota studies in vocational rehabilitation.

Deery, M. (2008). Talent management, work-life balance and retention strategies.International Journal of Contemporary Hospitality Management, 20(7), 792 - 806.

Downe, A., Loke, S. P., Ho, J. \& Taiwo, A. (2012). Corporate talent needs and availability in Malaysian service industry.International Journal of Business and Management, 7(2), 224-235.

Edwards, J. A. \& Billsberry, J. (2010). Testing a multidimensional theory of personenvironment fit.Journal of Managerial Issues, 22(4), 476-493.

Edwards, J.R. (1996). An examination of competing versions of the person-environment approach to stress.Academy Of Management Journal, 39(2), 292-339.

Eisner, S.P. (2005). Managing Generation Y.Sam Advanced Management Journal, 70(4), 4-15.

Elfenbein, H. A. \& O'Reilly, C. A. (2007). Fitting in: the effects of relational demography and person-culture fit on group process and performance.Group and Organization Management, 32(1), 109-142.

Firth, L., Mellor, D., Moore, K. \& Loquet, C. (2004). How can managers reduce employee intention to quit? Journal of Managerial Psychology, 19(2), 170-187.

Fornell, C. \& Larcker, D.F. (1981). Evaluating structural equation models with unobservable variables and measurement error.Journal of Marketing Research, 18(1), 39-50.

Giancola, F. (2006). The generation gap: more myth than reality.Human Resource Planning, 29(4), 32-37.

Giauque, D., Resenterra, F. \& Siggen, M. (2014). Antecedents of job satisfaction, organizational commitment and stress in a public hospital: a P-E fit perspective.Public Organization Review, 14(2), 201-228.

Griffeth, R.W., Hom, P. W. \&Gaertner, S. (2000). A Meta-Analysis of Antecedents and correlates of Employee Turnover: Update, Moderator tests, and Research implications for the next millennium. Journal of Management, 26(3), 463-488.

Griffeth, R. W. \& Hom, P. W. (1995). The employee turnover process.Research in personnel and human resources management, 13(3), 245-293.

Hair, J., Black, W., Babin, B., Anderson, R. \& Tatham, R. (2006). Multivariate data analysis, Upper saddle River, N.J.: Pearson Prentice Hall.

Hair, J.F., Anderson, R.E., Tatham, R.L. \& Black, W.C. (1998). Multivariate Data Analysis with Readings, Prentice-Hall, Englewood Cliffs, NJ

Han, D. \& Su, X. (2011). Managing Generation Y: recruiting and motivating. International Conference on Management and Service Science, Wuhan, China, pp. 1-4.

Hassan, M., Akram, A. \& Naz, S. (2012). The relationship between person organization fit, person-job-fit and turnover intention in banking sector of Pakistan: the mediating role of psychological climate.International Journal of Human Resource Studies, 2(3), 172.

Hochwarter, W., Kacmar, C., Perrewe, P. \& Johnson, D. (2003). Perceived organizational support as a mediator of the relationship between politics perceptions and work outcomes.Journal of Vocational Behavior, 63, 438-456.

House, R. \& Rizzo, J. (1972). Toward the measurement of organizational practices: scale development and validation.Journal of Applied Psychology, 56(5), 388.

Howe, N. \& Strauss, W. (2007). The next 20 years: how customers and workforce attitudes will evolve.Harvard Business Review, 85(7), 41-52.

Huang, C., Wang, Y., Wu, T. \& Wang, P. (2013). An Empirical analysis of the antecedents and performance consequences of using the moodle platform.International Journal of Information and Education Technology, 3(2), 217-221.

Hu \& Bentler. (1999). Cutoff criteria for fit indexes in covariance structure analysis: Conventional criteria versus new alternatives, Structural Equation Modeling. A Multidisciplinary Journal, 6(1), 1-55.

Josiam, B., Crutsinger, C., Reynolds, J. \& Vi Dotter, T. (2009). An empirical study of the work attitudes of generation y college students in the USA: the case of hospitality and merchandising undergraduate majors.Journal of Services Research, 9(1), 5.

Kim, H., Knight, D. \& Crutsinger, C. (2009). Generation Y employees' retail work experience: the mediating effect of job characteristics.Journal of Business Research, 62(5), 548-556. 
Karasek, R. A. (1979). Job demands, job latitude, and mental strain: implications for job redesign. Administrative Science Quarterly, 24, 285-308.

Kowske, B. J., Rasch, R. \& Wiley, J. (2010). Millennials' (lack of) attitude problem: An empirical examination of generation effects on work attitudes.Journal of Business and Psychology, 25(2), 265-279.

Kristof, A.L. (1996). Person-Organisation fit: an integrative review of its conceptualizations, measurement, and implications.Personnel Psychology, 49(1), 10-49.

Kristof-Brown, A.L., Zimmerman, R.D. \& Johnson, E.C. (2005). Consequences of individuals'fit at work: a metaanalysis of person-job, person-organisation, person-group, and person-supervisor fit.Personnel Psychology, 58(2), 281-342.

Kupperschmidt, B.R. (2000). Multigenerational employees: strategies for effective management.The Health Care Manager, 19(1), 65-76.

Lee, C., Hung, D. \& Ling, T. (2012). Work values of Generation Y pre-service teachers Malaysia, International Congress on Interdisciplinary Business and Social Sciences.Procedia - Social and Behavioral Sciences, $65,704-710$.

Lewin, K. (1935). Dynamic Theory of Personality. New York: Mcgraw-Hill.

Liu, B., Liu, J. \& Hu, J. (2010). Person-organization fit, job satisfaction, and turnover intention: an empirical study in the Chinese public sector. Social Behavior and Personality, 38(5), 615-626.

Lyons, S. (2004). An exploration of generational values in life and at work, Thesis submitted for Eric Sprot School of Business, Caleton University.

Macky, K., Gardner, D. \& Forsyth, S. (2008). Generational differences at work: introduction and overview.Journal of Managerial Psychology, 28(8), 857-861.

Marthandan, G., Jayashree, S. \& Yelwa, H. (2013). Acquiring key competencies in Malaysia, Proceedings of 23rd International Business Research Conference on 18 - 20 November, Melbourne, Australia.

Mathis, R. L. \& John, H. J. (2003). Human Resource Management, 10th edition, Cincinnati, OH: South-Western College Publishing.

Meyer, J. P., Stanley, D. J., Herscovitch, L. \& Topolnytsky, L. (2002). Affective, Continuance and Normative Commitment to the Organization: A Meta-Analysis of Antecedents, Correlates, and Consequences.Journal of Vocational Behavior, 61(1), 20-52.

Milfont, T. L. \& Fischer, R. (2010). Testing measurement invariance across groups: applications in crosscultural research.International Journal of psychological research, 3(1), 111-130.

Moynihan, D. P. \& Pandey, S. K. (2007). Finding workable levers over work motivation: comparing job satisfaction, job involvement, and organizational commitment.Administration and Society, 39(7), 803 $-832$.

Muchinsky, P. M. \& Monahan, C. J. (1987). what is person-environment congruence? supplementary versus complementary models of fit.Journal of Vocational Behavior, 31(3), 268- 277.

Nee, C., Jing, L., Xin, L., Yee, L. \& Lin, T. (2013). A Study of Employees' Turnover Intention among Generation Y in Fast- Food Industry, Unpublished Thesis, University of Multimedia.

Porter, L. W., Steers, R. M., Mowday, R. T. \& Boulian, P. V. (1974). Organizational Commitment, Job Satisfaction, and Turnover Among Psychiatric Technicians. Journal of Applied Psychology, 59(5), 603.

Queiri, A., Yusoff, W. F. W. \& Dwaikat, N. (2014). Generation-Y employees' turnover: work-values fit perspective.International Journal of Business and Management, 9(11), 199.

Schmitt, N., Oswald, F., Friede, A., Imus, A. \& Merritt, S. (2008). Perceived fit with an academic environment: attitudinal and behavioural outcomes.Journal of Vocational Behaviour, 72(3), 317-335.

Sheahan, P. (2007). Generation Y in Asia, Sydney: University Of Sydney.

Shore, L. M. \& Martin, H. J. (1989). Job satisfaction and organizational commitment in relation to work performance and turnover intentions.Human Relations, 42(7), 625-638.

Solnet, D. \& Hood, A. (2008). Generation Y as hospitality employees: framing a research agenda.Journal of Hospitality and Tourism Management, 15, 59-68.

Stevens, J.P. (1992). Applied Multivariate Statistics for the Social Sciences, 2nd edition. Hillsdale, NJ: Erlbaum.

Twenge, J. M. \& Campbell, W. K. (2009). The Narcissism Epidemic: Living In the Age of Entitlement, New York: Free Press.

Twenge, J. (2010). A Review of the Empirical Evidence on Generational Differences in Work Attitudes.Journal of Business Psychology, 25(2), 201-210. 
Vandenberg, R. J. \& Lance, C. E. (2000). A review and synthesis of the measurement invariance literature: suggestions, practices, and recommendations for organizational research.Organizational Research Methods, 3(1), 4-69.

Van Vianen, A. E.M. (2000). Person-Organization Fit: The Match between Newcomers' and Recruiters' Preferences for Organizational Cultures. Personnel Psychology, 53(1), 113-149.

Wan Yusoff, W., Queiri, A., Zakaria, S. \& Hisham, R. (2013). Generation-Y turnover intention in business process outsourcing sector, 2nd International Proceeding Conference on Management, Economics and Finance, Kota Kinabalu, Malaysia, 429 - 439.

Westerman, J. W. \& Cyr, L. A. (2004). An integrative analysis of person-organization fit theories.International Journal of Selection and Assessment, 12(3), 252-261.

Westerman, J. \& Yamamura, J. (2006). Generational preferences for work environment fit: effects on employee outcomes.Career Development International, 12(2), 150-161.

Wong, M., Gardiner, E. \& Lang, W. (2008). Generational differences in personality and motivation: do they exist and what are the implications for. Journal of Managerial Psychology, 23(8), 878-890. 